\title{
Correlation Shifts and Real Estate Portfolio Management
}

\author{
A Paper Presented at the ARES Annual Meeting \\ April 2002 \\ Naples, Florida
}

By

\author{
Stephen L. Lee \\ Department of Land Management and Development, \\ School of Business, The University of Reading, \\ Reading RG6 6AW, England.
}

Phone: +44 118931 6338, Fax: +44 118931 8172, E-mail: S.L.Lee@ reading.ac.uk

\begin{abstract}
The success of any diversification strategy depends upon the quality of the estimated correlation between assets. It is well known, however, that there is a tendency for the average correlation among assets to increase when the market falls and vice-versa. Thus, assuming that the correlation between assets is a constant over time seems unrealistic. Nonetheless, these changes in the correlation structure as a consequence of changes in the market's return suggests that correlation shifts can be modelled as a function of the market return. This is the idea behind the model of Spurgin et al (2000), which models the beta or systematic risk, of the asset as a function of the returns in the market. This is an approach that offers particular attractions to fund managers as it suggest ways by which they can adjust their portfolios to benefit from changes in overall market conditions.
\end{abstract}

In this paper the Spurgin et al (2000) model is applied to 31 real estate market segments in the UK using monthly data over the period 1987:1 to 2000:12. The results show that a number of market segments display significant negative correlation shifts, while others show significantly positive correlation shifts. Using this information fund managers can make strategic and tactical portfolio allocation decisions based on expectations of market volatility alone and so help them achieve greater portfolio performance overall and especially during different phases of the real estate cycle.

Keywords: Correlation Shifts, Asset Returns and Portfolio Management. 


\section{Correlation Shifts and Real Estate Portfolio Management}

\section{Introduction}

The benefits of diversification within real estate portfolios are well known; see Hamelink et al (2000) and Viezer (2000) for comprehensive reviews. These benefit accrue from the less than perfect correlation between the various market segments, i.e. if the correlation between market segments is low, spreading the portfolio across these segments should lead to a decrease in total risk and allows fund managers more opportunities to find properties with higher returns. In other words, the lower the level of correlation between assets the greater the potential for portfolio risk reduction and increased returns. The success of a particular diversification strategy consequently depends upon the quality of the estimated correlation between assets. It is well known, however, that there is a tendency for the average correlation among assets to change as markets rise and fall. Assuming that the correlation between assets is a constant over time therefore seems unrealistic. The better the estimation of the change in the correlation coefficients over time, the greater the potential benefits to the management of the real estate portfolio.

The traditional approach to estimating the correlation between assets is to use historic data over a fixed time period. Such an approach is poorly suited to studying changes in correlation over time, as a large number of observations are required just to estimate one correlation coefficient. Alternative estimation methods have been suggested that either have severe limitations or are not easy to implement; see Solnik and Roulet (2000). Recently, Spurgin, et al (2000) have proposed a simple way to estimate the changes in the correlation of an asset as a function of the general level of the market. This is an approach that offers particular attractions to fund managers as it suggest ways by which they can adjust their portfolios to benefit from changes in overall market conditions.

The remainder of the paper is organised as follows: the next section discusses the model proposed by Spurgin, et al (2000). The data is described in ection three. Section four presents the estimation results and section five the model predictions for various percentile values of market index. Section six then shows the implication for asset return characteristics, while section seven discusses the implications for portfolio asset allocation. Section eight concludes the paper and suggest future areas of research..

\section{Estimation of Correlation Coefficients}

The traditional approach to the estimation of the correlation coefficient between assets is to use a fixed number of time series observations with a sufficient large number of data points to provide statistically significant estimates. Such an estimation method is deficient in at least two areas. First, each pairwise correlation coefficient is computed separately; consequently the overall correlation between each asset has to be estimated from say the average of all pairwise coefficients. Secondly, the time series method provides only an unconditional estimate and so changes in correlation coefficients are difficult to judge. For instance, with monthly data and a two-year estimation window, ten years of data are needed simply to derive five independent correlation coefficients. Even 
using a "moving window" of overlapping observations (by replacing one month from the beginning of the data series with the latest observation) is unsatisfactory because any two successive correlation coefficients are based on almost identical data sets. Hence, a long time is needed for a permanent change in the general level of correlation across assets to be reflected in the estimation. While, a temporary change will go unnoticed because it affects only a few observations in the estimation window. In addition, it is well known that there is a tendency for the average correlation among assets to increase during bear markets and decrease in bull markets. However, this variation in the correlation structure across assets, as a consequence of changes in the market's return, suggests that correlation shifts could be modelled as a function of the returns of the market index.

\section{Single Index Market Model}

The simplest way to model changes in an asset's correlation with the market is to use the single index market model (SIMM) proposed by Sharpe (1963). Such an approach not only offers simplicity but also provides an improvement over the time series approach which assumes that the correlation coefficient is constant. The SIMM can be estimated by the following equation linking the returns of the asset to the returns of a market index:

$$
\mathrm{r}_{\mathrm{it}}=\alpha+\beta_{\mathrm{i}} \mathrm{r}_{\mathrm{mt}}+\varepsilon_{\mathrm{it}} \quad \mathrm{t}=1, \ldots \ldots \mathrm{T}
$$

where $r_{i t}$ is the return of the ith asset at time $t, r_{m t}$ is the return of the market index at time t, $\beta$ (beta) is the slope coefficient of the regression measuring the change in the asset's returns relative to those of the market and $\alpha$ (alpha) is a measure of the asset's returns independent of the market.

However, while offering an improvement over the use of time-series estimation methods such an approach has two serious drawbacks. First, for large changes in beta, the correlation coefficient could be greater than +1 or smaller than -1 , which is not possible. The second drawback is that a linear model implies that the pattern of correlation changes over time is symmetrical for market increases and decreases. However, when the real estate market is rising there is a tendency for properties to show divergent returns performance and so a lower average correlation, but during market declines the returns of assets tend to converge leading to a higher average correlation between the assets (Morrell, 1993, 1997 and Lee, 1998). This implies that the correlation across assets in rising and falling markets shows asymmetric behaviour.

\section{Quadratic Market Model}

To overcome these problems Spurgin, et al (2000) suggest modelling the beta (or systematic risk) of an asset as a linear function of the market return as in the following equation:

$$
\beta_{\mathrm{im}}=\mathrm{a}+\mathrm{br}_{\mathrm{m}}
$$


Where $\beta_{\mathrm{im}}$ is the beta coefficient between the individual asset and the market. Since beta in equation 2 is the slope of the return function, the asset's return function is the integral of the beta function given by the following equation:

$$
\mathrm{r}_{\mathrm{i}}=\int \beta_{\mathrm{im}}=a \mathrm{r}_{\mathrm{m}}+1 / 2 \mathrm{br}_{\mathrm{m}}^{2}+\mathrm{c}
$$

Equation 3 shows that the assets return is a quadratic function of the market return and so should be modelled by a quadratic market model (QMM), similar formulations of which can be found in the literature, most recently by Ferson and Harvey $(1991,1993)$.

Spurgin, et al (2000) propose that the parameters of equation 3 can be estimated by regressing the returns of the asset against the returns of the market and its squared returns using ordinary least squares (OLS) as in equation 4 :

$$
\hat{\mathrm{r}}_{\mathrm{it}}=\hat{\alpha}+\hat{\beta}_{1} \mathrm{r}_{\mathrm{mt}}+\hat{\beta}_{2}\left(\mathrm{r}_{\mathrm{mt}}-\overline{\mathrm{r}}_{\mathrm{m}}\right)^{2}+\varepsilon_{\mathrm{it}}
$$

where the squared market returns are adjusted to have a zero mean, to ensure that the quadratic function is centred around the mean return of the market.

Once the parameters of equation 4 have been estimated, the beta of the asset, dependent on the market return, can be derived by the following equation:

$$
\beta_{\mathrm{imt}}=\beta_{1}+\beta_{2}\left(\mathrm{r}_{\mathrm{mt}}-\overline{\mathrm{r}}_{\mathrm{m}}\right)^{2}
$$

Note that since the quadratic term is centred on the mean return of the market, the QMM beta, at time $\mathrm{t}$, will be the same as the SIMM beta when the market return equals its longrun average. At all other times the beta of the asset will deviate from that predicted by the SIMM depending on how much the market return is above, or below, its average value, i.e. the greater the volatility in the market. The sign of the quadratic, or beta shift, term $\left(\beta_{2}\right)$ will determine whether the asset reacts positively or negative to these changes in market volatility.

Assuming that the variance ratio between the asset and the market remains constant, the correlation coefficient between the asset and the market index is the beta function in equation 5 adjusted by the ratio of the standard deviations between the asset and the market index as follows:

$$
\rho_{\mathrm{im}}=\beta_{\mathrm{im}} \sigma_{\mathrm{i}} / \sigma_{\mathrm{m}}
$$

The sign of the correlation coefficient of the asset with the market thus depends on the sign of the asset's beta shift coefficient $\left(\beta_{2}\right)$. 


\section{Data}

The data used in this study comes from the Investment Property Databank (IPD) Monthly Index. The IPD Monthly Index measures returns to direct investment in commercial property from the performance of 54 institutional portfolios containing 2734 properties valued at $£ 10.6 \mathrm{bn}$ at the end of December 2000 . The data is sub-divided into three property-types (Retail, Office and Industrial) and a number of geographical regions making a total of 31 real estate market segments, the data covering the period 1987:1 to 2000:12. The returns of the market index are represented by the value-weighted performance of all the properties within the database. Monthly returns were calculated as the change in the logarithm of successive index values, that is $R_{t}=\log \left(I_{t}\right)-\log \left(I_{t-1}\right)$ where; $R_{t}$ is the return at time $t ; I_{t}$ is the total return index at time $t$ and $I_{-1}$ is the total return index at time $\mathrm{t}-1$.

\section{Estimation}

Table 1 presents the OLS estimations of the QMM and SIMM relationships between the various market segments and market index returns. Table 1 shows a number of features of interest. First, 17 of the beta shift coefficients are significant at better than the $10 \%$ level, hence for more than half of the sample the quadratic term significantly increases the explanatory power of the QMM over that of the SIMM. Secondly, the sign of the beta shift coefficient $\left(\beta_{2}\right)$ is negative for 8 of the market segments, the majority of which are within London and the Southeast. In contrast, the 9 market segments with significantly positive beta shift coefficients are concentrated in the retail and industrial sectors especially outside London. These significant beta shift coefficients imply that a $1 \%$ in the returns of the market index leads to significant shifts in the beta of the asset. For instance, the quadratic term coefficient $\left(\beta_{2}\right)$ for the City of London Office market segment indicates that for each $1 \%$ increase in the returns of the market index leads to a significant decrease in the City of London Office market beta by $0.3 \%$. In contrast, a $1 \%$ increase in the returns of the market index leads to significant increase of $0.2 \%$ in the beta of Industrial properties in the Northeast and Scotland.

\section{TABLE 1 ABOUT HERE}

Table 1 shows that the on average the QMM estimates of $\beta_{1}$ are almost identical to those of the SIMM, 0.978 compared with 0.990 . This provides evidence that the results in the first part of Table 1 are not driven by any interaction between the two explanatory variables. Further evidence is provides by the adjusted Rsquared values of the models. The adjusted R-squared values of the SIMM are nearly identical to those of the QMM. Therefore, the improvement in explanatory power can be attributed to the quadratic term. Nonetheless the beta shift coefficient $\left(\beta_{2}\right)$ explains very little in comparison to $\beta_{1}$, the market risk factor. Adding, on average, only slightly over $1 \%$ to the explanatory power over that of the SIMM. 
Table 1 shows that the intercept values $(\alpha)$ of the QMM are, on average, less than that for the SIMM, $-1.2 \%$ compared with $1.3 \%$ respectively. This results from a change in the intercept term for those market segments displaying significantly negative and positive beta shift coefficients. For those market segments with a significantly negative beta shift coefficient the intercept terms have a tendency to rise, while for those segments with significantly positive beta shift coefficients the intercepts tend to fall. However, since there are more significantly positive beta shift coefficients than negative the overall effect is a fall in alpha. This difference in alpha stems from the fact that a large negative (positive) coefficient implies that the asset will have lower (higher) returns on average than that predicted by the SIMM when the market moves up (due to decrease (increase) in correlation) or down (due to an increase (decrease) in correlation). Since the actual performance of the asset is the same in both regressions, the QMM compensates for the lower (higher) returns in the tail of the distribution by implying a higher (lower) return when the market index is at its average level, i.e. when $\left(r_{m}-\bar{r}_{m}\right)^{2}$ is close to zero.

The final column of Table 1 shows the calculation of the correlation shift coefficients due to a $1 \%$ change in the market index return, assuming that the ratio of variances between the market segment and the index is a constant. In line with the results for the beta shift coefficient a $1 \%$ change in the market index leads to a significant decrease in the correlation coefficient of the City of London Office market segment by $0.6 \%$ but a significant increase of $0.3 \%$ for Industrial properties in the Northeast and Scotland.

\section{Model Predictions}

Table 2 shows the resulting values for beta and the correlation coefficients for various values of the market index. The returns chosen represent the $2^{\text {nd }}, 25^{\text {th }}, 50^{\text {th }}, 75^{\text {th }}$, and $98^{\text {th }}$ percentile points for the monthly return distribution of the IPD Monthly Index. Table 2 shows that for those market segments which have significant positive, or negative, beta shift coefficients the betas and the correlation values changes dramatically as the market index returns go beyond the $75^{\text {th }}$ and $25^{\text {th }}$ percentiles towards the extremes of the return distribution. For instance, the beta value of the City of London Office more than doubles as the returns of the market index moves from the $75^{\text {th }}$ to the $98^{\text {th }}$ percentile, while there is a more than a four fold increase as the market index moves from the $25^{\text {th }}$ to the $2^{\text {nd }}$ percentile. In contrast between the $75^{\text {th }}$ and $25^{\text {th }}$ percentile there is only a minor change in beta values. This is because the quadratic term only begins to exert its influence on projected returns when the market index moves more than one standard deviation in either direction.

\section{TABLE 2 ABOUT HERE}

Table 2 also shows the one major weakness of the model. Assuming a linear model of this kind implies that for large changes in the market index can result in the correlation coefficients exceeding its bounds, i.e. +1 and -1 . For instance as seen in Table 2 the 
predicted value of the correlation coefficient of City of London Office when the market return at $2.7 \%$ (i.e. the $98^{\text {th }}$ percentile) the correlation coefficient is greater than -1 . In fact the City of London Office breaks the -1 value when the IPD Monthly Index shows a return greater than $1.7 \%$ per month (i.e. above the $88^{\text {th }}$ percentile). However, it must be remembered the model outlined in equation 5 estimates the beta of the market segment not the correlation coefficient. The correlation coefficients are derived using equation 6 assuming no change in the ratio of variances between the market index and the individual segment. It may be that as the market returns moves into the extremes of its distribution the ratio of variances may change sufficiently from their long run averages such that the correlation coefficients do not exceed their bounds.

\section{The Implications for Asset Returns}

The model above shows that changes in the correlation coefficients through time result from changes in beta induced by movements in the market index from its long-run average. These beta and correlation shifts have a number of important implications for the return characteristics of the asset.

First, the significance of the beta shift coefficients is particularly important for the returns of a particular asset during volatile and calmer periods of the market. As shown in equation 3 asset returns are modelled as a function of the assets beta. Thus, as the returns of the market become more volatile those assets that have a significantly negative beta shift coefficient will display lower beta coefficients than that predicated by the SIMM. As a consequence these assets will tend to offer lower returns on average during the volatile phase of the real estate cycle. In contrast, those assets displaying significantly positive beta shift coefficients should offer higher average returns in the more volatile market phase. However, during calmer periods in the market, when the returns of the index are close to its long-run average, the beta shift coefficients will have little impact on the overall beta, consequently both types of assets will perform more in line with that predicted by the SIMM. In other words the market segments should show a lower (higher) average return in volatile rather than calmer periods of the real estate cycle the more negative (positive) the beta shift coefficient.

Secondly, significantly negative or positive beta shift coefficients also have implications for the skewness of the returns distribution. A distribution that is positively skewed will have its mean near the minimum and so returns above the mean can be particularly large. Negative skewness implies that the average is near the maximum and so returns below the mean can be extremely low, i.e. very negative. As investors are assumed to prefer higher returns to lower returns, investors should prefer assets offering positive skewness to those showing negative skewness. From equation 4 it can be easily seen that for those market segments with negative beta shift coefficients the estimated return from the QMM will be less than that predicted by the SIMM. Consequently, the estimated returns from the QMM will have a greater tendency to display lower positive and more negative returns than those predicted by the SIMM. This effect will become more exaggerated as market conditions become more volatile, i.e. as the impact of the quadratic term has greater influence on expected returns. In other words, the mean return of such market 
segments will be closer to the maximum indicating the distribution is negatively skewed. In contrast, market segments showing positive beta shift coefficients should display positive skewness, especially during the volatile periods.

Finally, assets with significant beta shift coefficients also display significant correlation shifts. Therefore, the returns of assets that show significantly negative correlation shifts will become progressively more detached from the returns of the market, the greater the volatility in the market index. In contrast the market segments with significantly positive correlation shifts should become progressively more closely aligned with the returns of the market during the more volatile market periods. Consequently market segments with significantly negative correlation shifts should display greater tracking error risk (TER) than those segments with positive correlation shifts during the volatile phases. In contrast during calmer periods, when the returns of the market are closer to its long-run average, the beta shift coefficient has only a minor influence on the calculation of the correlation of the asset and the market. Hence, during the calmer periods the returns of all assets will be more closely associated with the market than during the volatile market period. Accordingly, TER should be lower for all market segments during the calmer periods than the volatile periods. Hence the market segments with positive correlation shift coefficients should display lower TER overall than those segments with negative correlation shift coefficients.

All these contentions are confirmed in Tables 3, 4 and 5.

\section{TABLE 3 ABOUT HERE}

Table 3 shows the average returns of the 31 market segments, over the whole period and for various sub-periods, ranked by their beta shift coefficient, from lowest to highest. Table 3 shows that the real estate market segments that have significant negative beta shift coefficients $\left(\beta_{2}\right)$ earned most of their return in the calmer periods of the market ${ }^{1}$. For instance, City of London Offices earned an average return of $-0.03 \%$ per month during the volatile phases of the market and an average return of $0.64 \%$ per month in the calmer periods, a difference that is significant at the $2 \%$ level $^{2}$. In contrast, market segments with significant positive beta shift coefficients earned the greater part of their overall return in the volatile periods rather than the calmer periods. For example, Industrial properties in the Northeast and Scotland earned $1.79 \%$ per month, on average, during the volatile phases compared with $1.1 \%$ per month in the calmer periods, a difference that is significant at the $1 \%$ level. However, as shown in the final row of Table 3 , although, overall there is a significant and positive correlation ${ }^{3}$ between the beta shift coefficients and the average returns of the market segments in the volatile phases of the

\footnotetext{
${ }^{1}$ Finding those periods when the returns of the IPDMI were greater than, or less than, one standard deviation defined the volatile phases of the market.

2 Based on a one-tailed t-test.

${ }^{3}$ Based on the Spearman rank correlation test to account for any non-normality in the data.
} 
real estate cycle (0.50) there is no relationship during the calmer periods (0.04). Consequently, the positive relationship is insignificant overall $(0.20)$.

However, it is during the "up-market" and "down-market"4 phases of the volatile market returns that the difference in performance between the positive and negative beta shift market segments is more clearly shown. In the volatile "up-market" periods there is little to choose in performance between the various market segments. In other words, all property performs well in the market boom; hence, as is to be expected, there is an insignificant relationship (0.06) between the beta shift coefficients and the average returns of the segments. During the volatile "down-market" phases, however, market segments with negative beta shift coefficients show significant negative performance. In contrast, for those market segments with positive beta shift coefficients there is a tendency for the investments to show only slightly negative, or even positive returns performance. Thus, there is a highly significantly positive relationship (0.73) between the beta shift coefficients and average returns during the volatile down market periods. As the market segments with negative beta shifts tend to be in London and the Southeast this implies that the further away from the South the better the return performance during market downturns. This confirming the findings of Lee and Byrne (1998) and Eichholtz et al (1995) who both find that average returns improve the greater the distance the market segment is from London and the Southeast. Finally, as is to be expected, the calmer periods of the real estate cycle show no relationship between the beta shift coefficients and average segment returns, in either "up-market", "down-market" or overall $^{5}$.

\section{TABLE 4 ABOUT HERE}

Table 4 presents the skewness statistics of the 31 market segments. A skewness value greater than 1 or less than -1 indicates a highly skewed distribution; values between 0.5 and 1 or -0.5 and -1 indicate moderate skewness, while values between 0.5 and -0.5 indicates that the distribution is fairly symmetric. Table 4 shows those assets showing negative beta shifts also tend to display negative skewness overall. In contrast, the market segments, which have positive beta shift coefficients, tend to display greater positive skewness. Indeed, there is a significantly positive relationship between the beta shift coefficients and the skewness of the market segments overall (0.68).

\footnotetext{
4 The up-market phases, in the volatile period, is defined as those periods when the returns of the IPD Monthly Index were gre ater than one standard deviation above the mean. Down-market periods are defined as those periods in the volatile phases when the returns are greater than one standard deviation below the mean.

5 The up-market phase, in the calm periods, is defined as those periods when the returns of the IPD Monthly Index were greater than the mean but below one standard deviation above the mean. Downmarket periods are defined as those periods in the calm phases when the returns are less than the mean but above one standard deviation below the mean.
} 
It is during the volatile phases of the real estate cycle, however, that the impact negative skewness has on return performance is most clearly seen. During the volatile "upmarket" phases there no relationship between the beta shift coefficients and market segments skewness, with a Spearman rank correlation coefficient of -0.14 , as all market segments are performing well. However, during the volatile "down-market" periods there is a significantly positive correlation $(0.51)$ between the beta shift coefficients and skewness. That is, market segments with negative beta shift coefficients tend to show greater negative skewness in market downturns than market segments displaying positive beta shift coefficients. In other words market segments with negative beta shifts display greater downside risk during volatile downturns, i.e. when it is least desired.

In contrast, during the calmer periods the situation is reversed. There is a significantly positive relationship between the beta shift coefficients and skewness in the "up-market" phases rather than the "down-market" periods. In other words market segments with positive beta shift coefficients have greater potential to offer above average returns in market upturns than those segments with negative beta shift coefficients. However, during the calmer downturn there is little to choose between the market segments.

This implies all things being equal, that increasing the positive skewness of a real estate fund should reduce the required return of the fund, since investors are compensated by the potential of higher returns and a reduction in downside risk, especially during volatile downturns of the real estate cycle. Thus, the greater the positive beta shift coefficient of the market segment the greater the positive skewness and so the greater the desirability of the market segment if the market is expected to enter a downturn.

\section{TABLE 5 ABOUT HERE}

Table 5 shows the TER of the various market segments. The TER of an asset is defined at the standard deviation of the relative return performance of the asset and the market benchmark. Thus, a TER risk of $1.5 \%$ means hat $95 \%$ of the time the asset will under or out- perform the market benchmark by up to $3 \%$ per month. In other words, the greater the TER the greater the probability that the market segment will show much higher and lower performance than the market index. For instance, the TER for City of London Offices indicates that on average, 19 times out of 20, the returns of this market segment will under- or out- perform the market index by up to $2.6 \%$ per month. In contrast, Industrial properties in the Northeast and Scotland will under- or out- perform the market index by $1.5 \%, 95 \%$ of the time. Table 5 also shows, as is to be expected, that TER is greater for nearly all the market segments during the volatile phases of the real estate cycle compared with the calmer periods. In addition, TER is only significantly negatively correlated with the beta shift coefficients during the calmer periods (-0.38) compared with the volatile periods $(-0.25)$. Accordingly, Table 5 shows the association between the beta shift coefficients and TER is weak overall $(-0.11)$. 


\section{Implication for Portfolio Construction}

If the correlation between a market segment and an investor's portfolio changes in a predicable way, that information can be useful in determining the optimal allocation of assets. Hence if the results above are indicative of the future performance of these real estate market segments they will help fund manager make strategic and tactical asset allocation decisions based on expectations of market volatility alone.

At the strategic asset allocation (SAA) level a risk-averse investor with a significant exposure to a market segment that shows a negative correlation shift would benefit from adding market segments with a positive beta shift, as those markets will generally educe the downside risk (skewness) of the portfolio. In a similar vein a fund manger eager to reduce the TER of the portfolio should try to overweight the portfolio into market segments with significantly positive correlation shift coefficients, irrespective of the expected phase of the real estate cycle.

Once these SAA weights have been determined the fund manger may wish to modify the portfolio allocations by making tactical asset allocation (TAA) decisions to exploit predicted correlation shifts resulting from changes in the expected volatility of the market. The results above can help managers make more informed TAA decisions. For instance, if it is expected that the market is about enter a volatile "down-market" phase, the fund manager should consider adjusting the fund's current exposure by increasing the funds weighting into those market segments that display significantly positive correlation shifts with the market. This should limit the downside risk (skewness) of the fund and so minimise losses, when it is most needed. In contrast, if it is predicted that the market is about to enter an "up-market" phase, i.e. start to rise above long-run average, a concentration of the portfolio into those segments predicted to out-perform the market benchmark is all that is needed; as all segments tend to perform well, show little differences in terms of negative skewness and is unlikely to have any serious impact TER.

\section{Conclusions}

This paper presents a simple method of estimating the changes in an assets beta as a function of the returns of the market index. Then using these beta estimates changes in the assets correlation with the market index can be modelled as a function of the markets volatility. Using these results it is possible to identify a number of key return characteristics of the assets. First, the model shows that for those market segments with significantly negative beta shifts perform better in calmer periods of the market. In contrast, those market segments showing significant positive beta shifts earn the greater part of their return during the volatile periods. Secondly, those market segments with significantly negative beta shifts display negative skewness, while those with positive beta shifts display positive skewness, especially during market downturns. Finally the market segments with significant negative beta shifts also have significantly negative correlation shifts, while those market segments with significantly positive beta shift 
coefficients show significantly positive correlation shifts. The greater the negative (positive) shifts in the correlation of the asset with the market index the greater the likelihood that the market segment will show higher (lower) TER. To the extent that these changes in correlation represent regularities in the performance of real estate market segments, fund managers can make use of this information to make strategic and tactical asset allocation decisions based on expectations of market volatility alone. In this way real estate fund managers should have greater control of the funds performance overall and especially during the different phases of the real estate cycle.

However, whilst the model presents a better representation of the correlation between real estate market segments and the market over time, than simply assuming a constant correlation, the model is not without its faults. As shown above it is still possible for the estimated values to be greater than the bounds of the correlation coefficient, i.e. +1 and 1. In addition the explanatory power of the quadratic term is weak. Thus, extensions to the model could be developed which incorporate factors that have greater explanatory power and alleviate the tendency of the model to overshoot the feasible bounds. 


\section{References}

Eichholtz, P. M. A., Hoesli, M., MacGregor, B. D. and Nanthakumaran, N. (1995) Real Estate Diversification by Property-type and Region, Journal of Property Finance, 6, 3, 39-62.

Ferson, W. and Harvey, C.R. (1991) The Variation of Economic Risk Premiums, Journal of Political Economy, 99, 2, 385-415.

Ferson, W. and Harvey, C.R. (1993) The Risk and Predictability of International Equity, Review of Financial Studies, 6, 3, 527-566.

Hamelink, F., Hoesli, M., Lizieri, C. and MacGregor, B.D. (2000) Homogeneous Commercial Property Markets Groupings and Portfolio Construction in the United Kingdom, Environment and Planning A, 32, 323-344.

Lee, S.L. (1998) The Inter-Temporal Stability of Real Estate Returns: An Empirical Investigation, Working Papers in Land Management and Development, 04/98, pp. 23.

Lee S.L. and Byrne P.J. (1998) Diversification by Sector, Region or Function? A Mean Absolute Deviation Optimisation, Journal of Property Valuation and Investment, 16, 1, $38-56$.

Morrell, G.D. (1993) Fund Structure or Stock Selection? A Decomposition of Relative Returns in the UK Property Market, A Paper presented to the Second IPD Investment Strategies Conference, 17-18 November, Brighton.

Morrell, G.D. (1997) Property Risk and Portfolio Construction, A Paper presented to the Sixth IPD Investment Strategies Conference, 27-28 November, Brighton.

Sharpe, W.F. (1963) A Simplified Model of Portfolio Analysis, Management Science, January, 277-293.

Solnick, B. and Roulet, J. (2000) Dispersion as Cross-Sectional Correlation, Financial Analysts Journal, Jan/Feb, 54-61.

Spurgin, R., Martin, G. and Schneeweis, T. (2000) A Method of Estimating Changes in Correlation Between Assets and its Application to Hedge Fund Investment, Journal of Asset Management, 1, 3, 217-230.

Viezer, T.W. (2000) Evaluating "Within Real Estate" Diversification Strategies, Journal of Real Estate Portfolio Management, 6, 1, 75-98. 
Table 1: Regression Results for the QMM and the SIMM: Monthly Data 1987:1 to 2000:12

\begin{tabular}{|c|c|c|c|c|c|c|c|c|}
\hline \multirow[b]{2}{*}{ Market Segment } & \multicolumn{4}{|c|}{ Quadratic Market Model } & \multicolumn{3}{|c|}{ Single Index Market Model } & Correlation \\
\hline & $\boldsymbol{\alpha}$ & $\boldsymbol{\beta}_{1}$ & $\boldsymbol{\beta}_{2}$ & Adj Rsq & $\alpha$ & $\boldsymbol{\beta}_{1}$ & Adj Rsq & 1\% Change \\
\hline Retail Central London & 0.071 & 1.085 & -0.073 & 46.5 & 0.034 & 1.068 & 46.4 & -0.11 \\
\hline Retail Rest of London & 0.012 & 0.814 & 0.046 & 69.8 & 0.036 & 0.825 & 69.6 & 0.05 \\
\hline Retail Inner South East & $-0.245 * * *$ & 0.933 & $0.114 * * *$ & 66.0 & $-0.186 * * *$ & 0.960 & 64.5 & $0.14 * * *$ \\
\hline Retail Outer South East & -0.100 & 0.805 & $0.097 * * *$ & 63.0 & -0.049 & 0.828 & 61.6 & $0.10 * * *$ \\
\hline Retail Eastern & -0.079 & 0.810 & 0.047 & 63.1 & -0.054 & 0.821 & 62.9 & 0.05 \\
\hline Retail South West & $-0.125 * *$ & 0.802 & $0.088 * * *$ & 69.9 & -0.079 & 0.823 & 68.6 & $0.09 * * *$ \\
\hline Retail East Midlands & 0.040 & 0.753 & $0.180 * * *$ & 58.4 & $0.133^{*}$ & 0.795 & 53.6 & $0.19 * * *$ \\
\hline Retail West Midlands & -0.044 & 0.748 & $0.103 * * *$ & 62.0 & 0.009 & 0.772 & 60.3 & $0.10 * * *$ \\
\hline Retail Yorkshire $\&$ Humberside & 0.002 & 0.780 & $0.101 * * *$ & 62.1 & 0.054 & 0.803 & 60.6 & $0.10 * * *$ \\
\hline Retail North West & -0.009 & 0.836 & 0.046 & 50.6 & 0.015 & 0.847 & 50.6 & 0.05 \\
\hline Retail North East & 0.083 & 0.614 & 0.017 & 29.8 & 0.092 & 0.618 & 30.2 & 0.02 \\
\hline Retail Scotland & $0.159 * *$ & 0.747 & $0.093 * *$ & 47.7 & $0.207 * * *$ & 0.769 & 46.8 & $0.10 * *$ \\
\hline Retail Wales & $0.253 * * *$ & 0.610 & 0.117 & 38.1 & $0.314 * * *$ & 0.637 & 36.2 & 0.12 \\
\hline Offices City of London & $-0.416 * * *$ & 1.316 & $-0.306 * * *$ & 44.3 & $-0.575 * * *$ & 1.243 & 40.2 & $-0.60 * * *$ \\
\hline Offices Mid-Town & $-0.608 * * *$ & 1.632 & -0.050 & 64.2 & $-0.634 * * *$ & 1.620 & 64.3 & -0.10 \\
\hline Offices West End & $-0.204 *$ & 1.471 & $-0.153 * *$ & 62.4 & $-0.283 * * *$ & 1.435 & 61.4 & $-0.28 * *$ \\
\hline Offices Rest of London & -0.031 & 1.063 & 0.014 & 62.5 & -0.024 & 1.066 & 62.8 & 0.02 \\
\hline Offices Inner South East & $-0.120 * *$ & 1.140 & $-0.120 * * *$ & 80.0 & $-0.182 * * *$ & 1.112 & 78.5 & $-0.15 * * *$ \\
\hline Offices Outer South East & -0.114 & 0.987 & 0.028 & 57.0 & -0.099 & 0.993 & 57.2 & 0.04 \\
\hline Offices Eastern & $-0.215 *$ & 1.222 & 0.085 & 51.5 & -0.171 & 1.242 & 51.4 & 0.15 \\
\hline Offices South West & $-0.238 * * *$ & 1.223 & 0.090 & 62.3 & $-0.191 * *$ & 1.244 & 61.9 & 0.14 \\
\hline Offices Midlands \& Wales & $0.227 * *$ & 0.751 & $0.095^{*}$ & 38.5 & $0.276 * * *$ & 0.773 & 37.8 & $0.12 *$ \\
\hline Offices Rest of England & 0.178 & 0.987 & $0.185^{* * *}$ & 44.3 & $0.274 * *$ & 1.031 & 42.1 & $0.29 * * *$ \\
\hline Offices Scotland & $-0.200 * *$ & 1.048 & 0.101 & 52.1 & -0.148 & 1.072 & 51.6 & 0.15 \\
\hline Industrials London & $0.245 * * *$ & 1.020 & -0.027 & 60.6 & $0.231 * * *$ & 1.014 & 60.8 & -0.04 \\
\hline Industrials Inner South East & $0.083 * * *$ & 1.019 & -0.019 & 66.1 & 0.074 & 1.014 & 66.3 & -0.02 \\
\hline Industrials Outer South East & 0.229 & 0.968 & 0.068 & 61.1 & $0.264 * * *$ & 0.984 & 60.8 & 0.09 \\
\hline Industrials Eastern & 0.057 & 1.210 & -0.025 & 67.9 & 0.044 & 1.205 & 68.0 & -0.04 \\
\hline Industrials South West & $0.218 * * *$ & 0.976 & $0.162 * * *$ & 61.0 & $0.301 * * *$ & 1.014 & 58.6 & $0.21 * * *$ \\
\hline Industrials Midlands \& Wales & $0.181 * *$ & 1.064 & $0.179 * * *$ & 65.4 & $0.273 * * *$ & 1.106 & 62.6 & $0.25 * * *$ \\
\hline Industrials Northeast $\&$ Scotland & $0.330 * * *$ & 0.901 & $0.235 * * *$ & 59.2 & $0.452 * * *$ & 0.956 & 53.5 & $0.31 * * *$ \\
\hline Average & -0.012 & 0.978 & 0.049 & 57.7 & 0.013 & 0.990 & 56.5 & 0.050 \\
\hline
\end{tabular}

Note: All $\beta_{1}$ coefficients are significant at the $1 \%$ level. * indicates significance at the $10 \%, * *$ indicates significance at the $5 \%$ level, *** indicates significance at the $1 \%$ level. 
Table 2: Model Predictions of Beta and The Correlation Coefficients

\begin{tabular}{|c|c|c|c|c|c|c|c|c|c|c|}
\hline \multirow{4}{*}{$\begin{array}{l}\text { Percentile } \\
\text { Return } \\
\text { Market Segment }\end{array}$} & \multicolumn{10}{|c|}{ Predicted Beta and Correlation Values at Market Extremes } \\
\hline & \multirow{2}{*}{\multicolumn{2}{|c|}{$\begin{array}{c}\left(2^{\text {nd }}\right) \\
-0.8 \%\end{array}$}} & \multirow{2}{*}{\multicolumn{2}{|c|}{$\begin{array}{l}\left(25^{\mathrm{th}}\right) \\
0.3 \%\end{array}$}} & \multirow{2}{*}{\multicolumn{2}{|c|}{$\begin{array}{l}\left.\mathbf{5 0}{ }^{\text {th }}\right) \\
\mathbf{0 . 8 \%}\end{array}$}} & \multirow{2}{*}{\multicolumn{2}{|c|}{$\begin{array}{l}\left(75^{\mathrm{th}}\right) \\
1.3 \%\end{array}$}} & \multirow{2}{*}{\multicolumn{2}{|c|}{$\begin{array}{l}\left(98^{\mathrm{th}}\right) \\
2.7 \%\end{array}$}} \\
\hline & & & & & & & & & & \\
\hline & Beta & Corr. & Beta & Corr. & Beta & Corr. & Beta & Corr. & Beta & Corr. \\
\hline Retail Central London & 0.07 & 0.11 & -0.01 & -0.01 & -0.05 & -0.08 & -0.09 & -0.13 & -0.19 & -0.29 \\
\hline Retail Rest of London & -0.03 & -0.03 & 0.02 & 0.02 & 0.05 & 0.04 & 0.07 & 0.07 & 0.13 & 0.13 \\
\hline Retail Inner South East & -0.08 & -0.09 & 0.04 & 0.05 & 0.10 & 0.12 & 0.16 & 0.19 & 0.32 & 0.38 \\
\hline Retail Outer South East & -0.07 & -0.07 & 0.03 & 0.04 & 0.09 & 0.09 & 0.14 & 0.14 & 0.27 & 0.29 \\
\hline Retail Eastern & -0.03 & -0.03 & 0.02 & 0.02 & 0.05 & 0.05 & 0.07 & 0.07 & 0.14 & 0.14 \\
\hline Retail South West & -0.06 & -0.06 & 0.03 & 0.03 & 0.08 & 0.08 & 0.12 & 0.12 & 0.25 & 0.25 \\
\hline Retail East Midlands & -0.13 & -0.14 & 0.05 & 0.06 & 0.15 & 0.17 & 0.25 & 0.27 & 0.50 & 0.54 \\
\hline Retail West Midlands & -0.07 & -0.07 & 0.03 & 0.03 & 0.09 & 0.09 & 0.14 & 0.14 & 0.29 & 0.29 \\
\hline Retail Yorkshire \&Humberside & -0.07 & -0.07 & 0.03 & 0.04 & 0.09 & 0.09 & 0.14 & 0.15 & 0.28 & 0.29 \\
\hline Retail North West & -0.03 & -0.03 & 0.02 & 0.02 & 0.05 & 0.05 & 0.07 & 0.08 & 0.13 & 0.16 \\
\hline Retail North East & -0.01 & -0.01 & 0.01 & 0.01 & 0.02 & 0.02 & 0.03 & 0.03 & 0.05 & 0.06 \\
\hline Retail Scotland & -0.06 & -0.07 & 0.03 & 0.04 & 0.08 & 0.09 & 0.13 & 0.15 & 0.26 & 0.29 \\
\hline Retail Wales & -0.09 & -0.09 & 0.04 & 0.04 & 0.10 & 0.11 & 0.16 & 0.17 & 0.33 & 0.34 \\
\hline Offices City of London & 0.25 & 0.49 & -0.07 & -0.13 & -0.24 & -0.46 & -0.39 & -0.77 & -0.82 & -1.61 \\
\hline Offices Mid-Town & 0.06 & 0.11 & 0.00 & 0.01 & -0.02 & -0.05 & -0.05 & -0.10 & -0.12 & -0.24 \\
\hline Offices West End & 0.13 & 0.25 & -0.03 & -0.05 & -0.11 & -0.20 & -0.19 & -0.34 & -0.40 & -0.74 \\
\hline Offices Rest of London & 0.00 & 0.00 & 0.01 & 0.02 & 0.02 & 0.03 & 0.03 & 0.04 & 0.05 & 0.07 \\
\hline Offices Inner South East & 0.10 & 0.13 & -0.02 & -0.02 & -0.09 & -0.11 & -0.15 & -0.18 & -0.32 & -0.40 \\
\hline Offices Outer South Eeast & -0.01 & -0.02 & 0.02 & 0.02 & 0.03 & 0.04 & 0.05 & 0.06 & 0.08 & 0.11 \\
\hline Offices Eastern & -0.05 & -0.09 & 0.03 & 0.06 & 0.08 & 0.14 & 0.12 & 0.22 & 0.24 & 0.42 \\
\hline Offices South West & -0.06 & -0.09 & 0.04 & 0.06 & 0.09 & 0.13 & 0.13 & 0.21 & 0.26 & 0.41 \\
\hline Offices Midlands \& Wales & -0.07 & -0.08 & 0.03 & 0.04 & 0.08 & 0.11 & 0.13 & 0.17 & 0.27 & 0.33 \\
\hline Offices Rest of England & -0.13 & -0.21 & 0.06 & 0.09 & 0.16 & 0.25 & 0.26 & 0.40 & 0.52 & 0.82 \\
\hline Offices Scotland & -0.07 & -0.10 & 0.04 & 0.05 & 0.09 & 0.14 & 0.14 & 0.21 & 0.29 & 0.43 \\
\hline Industrials London & 0.03 & 0.04 & 0.00 & 0.00 & -0.01 & -0.02 & -0.03 & -0.03 & -0.06 & -0.08 \\
\hline Industrials Inner South East & 0.02 & 0.03 & 0.01 & 0.01 & 0.00 & -0.01 & -0.01 & -0.02 & -0.04 & -0.05 \\
\hline Industrials Outer South Easte & -0.04 & -0.05 & 0.03 & 0.03 & 0.07 & 0.08 & 0.10 & 0.13 & 0.20 & 0.25 \\
\hline Industrials Eastern & 0.03 & 0.05 & 0.01 & 0.01 & -0.01 & -0.01 & -0.02 & -0.03 & -0.06 & -0.08 \\
\hline Industrials South West & -0.12 & -0.15 & 0.05 & 0.07 & 0.14 & 0.19 & 0.22 & 0.30 & 0.45 & 0.60 \\
\hline Industrials Midlands \& Wales & -0.13 & -0.18 & 0.06 & 0.08 & 0.16 & 0.22 & 0.25 & 0.35 & 0.50 & 0.70 \\
\hline Industrials Northeast $\&$ Scotland & -0.17 & -0.23 & 0.07 & 0.09 & 0.20 & 0.26 & 0.32 & 0.42 & 0.65 & 0.85 \\
\hline
\end{tabular}


Table 3: Mean Return of the Market Segments Ranked by Beta Shift Coefficient

\begin{tabular}{|c|c|c|c|c|c|c|c|c|}
\hline \multirow[b]{2}{*}{ Market Segment } & \multirow{2}{*}{$\begin{array}{l}\text { Beta } \\
\text { Shift }\end{array}$} & \multirow{2}{*}{$\begin{array}{l}\text { Overall } \\
\text { Average }\end{array}$} & \multicolumn{3}{|c|}{ Volatile } & \multicolumn{3}{|c|}{ Calm } \\
\hline & & & Up & Down & Overall & Up & Down & Overall \\
\hline Offices City of London & -0.31 & 0.47 & 1.83 & -1.81 & -0.03 & 1.28 & 0.06 & 0.64 \\
\hline Offices West End & -0.15 & 0.93 & 3.27 & -1.13 & 1.02 & 1.39 & 0.46 & 0.90 \\
\hline Offices Inner South East & -0.12 & 0.76 & 2.32 & -0.82 & 0.71 & 1.26 & 0.33 & 0.77 \\
\hline Retail Central London & -0.07 & 0.93 & 2.45 & -0.58 & 0.90 & 1.40 & 0.54 & 0.95 \\
\hline Offices Mid-Town & -0.05 & 0.73 & 3.15 & -1.67 & 0.68 & 1.38 & 0.19 & 0.75 \\
\hline Industrials London & -0.03 & 1.09 & 2.57 & -0.35 & 1.08 & 1.58 & 0.65 & 1.09 \\
\hline Industrials Eastern & -0.03 & 1.06 & 3.14 & -0.57 & 1.24 & 1.47 & 0.58 & 1.00 \\
\hline Industrials Inner South East & -0.02 & 0.93 & 2.38 & -0.41 & 0.95 & 1.46 & 0.44 & 0.92 \\
\hline Offices Rest of London & 0.01 & 0.88 & 2.41 & -0.58 & 0.88 & 1.37 & 0.44 & 0.88 \\
\hline Retail North East & 0.02 & 0.61 & 1.61 & -0.21 & 0.68 & 0.74 & 0.46 & 0.59 \\
\hline Offices Outer South Eeast & 0.03 & 0.74 & 2.44 & -0.35 & 1.01 & 1.11 & 0.24 & 0.65 \\
\hline Retail Rest of London & 0.05 & 0.73 & 2.01 & -0.21 & 0.87 & 1.10 & 0.31 & 0.69 \\
\hline Retail North West & 0.05 & 0.73 & 2.07 & -0.26 & 0.88 & 1.03 & 0.37 & 0.68 \\
\hline Retail Eastern & 0.05 & 0.64 & 1.96 & -0.43 & 0.73 & 0.98 & 0.28 & 0.61 \\
\hline Industrials Outer South Easte & 0.07 & 1.09 & 2.78 & -0.04 & 1.34 & 1.47 & 0.61 & 1.02 \\
\hline Offices Eastern & 0.08 & 0.88 & 3.03 & -0.62 & 1.16 & 1.21 & 0.41 & 0.79 \\
\hline Retail South West & 0.09 & 0.61 & 1.95 & -0.40 & 0.75 & 0.88 & 0.30 & 0.57 \\
\hline Offices South West & 0.09 & 0.86 & 2.91 & -0.77 & 1.03 & 1.18 & 0.47 & 0.80 \\
\hline Retail Scotland & 0.09 & 0.86 & 1.98 & -0.13 & 0.90 & 1.13 & 0.58 & 0.84 \\
\hline Offices Midlands \& Wales & 0.09 & 0.93 & 2.37 & 0.08 & 1.20 & 1.16 & 0.56 & 0.84 \\
\hline Retail Outer South East & 0.10 & 0.65 & 2.17 & -0.32 & 0.89 & 0.94 & 0.24 & 0.57 \\
\hline Retail Yorkshire \&Humberside & 0.10 & 0.73 & 2.14 & -0.28 & 0.90 & 0.97 & 0.41 & 0.68 \\
\hline Offices Scotland & 0.10 & 0.76 & 2.67 & -0.43 & 1.08 & 1.06 & 0.29 & 0.65 \\
\hline Retail West Midlands & 0.10 & 0.66 & 1.84 & -0.34 & 0.73 & 0.98 & 0.34 & 0.64 \\
\hline Retail Inner South East & 0.11 & 0.62 & 2.13 & -0.47 & 0.80 & 0.99 & 0.19 & 0.57 \\
\hline Retail Wales & 0.12 & 0.85 & 1.86 & 0.18 & 1.00 & 1.11 & 0.53 & 0.80 \\
\hline Industrials South West & 0.16 & 1.16 & 3.12 & 0.22 & 1.63 & 1.50 & 0.56 & 1.00 \\
\hline Industrials Midlands \& Wales & 0.18 & 1.21 & 3.30 & 0.17 & 1.70 & 1.47 & 0.67 & 1.05 \\
\hline Retail East Midlands & 0.18 & 0.80 & 2.29 & 0.01 & 1.13 & 1.11 & 0.33 & 0.70 \\
\hline Offices Rest of England & 0.19 & 1.14 & 3.05 & -0.03 & 1.47 & 1.40 & 0.71 & 1.04 \\
\hline Industrials Northeast $\&$ Scotland & 0.23 & 1.26 & 3.28 & 0.36 & 1.78 & 1.41 & 0.80 & 1.09 \\
\hline Average & & 0.85 & 2.47 & -0.39 & $\mathbf{1 . 0 0}$ & 1.21 & $\mathbf{0 . 4 3}$ & $\mathbf{0 . 8 0}$ \\
\hline Correlation with Beta Shift Coe & fficient & $\mathbf{0 . 2 0}$ & 0.06 & $0.73^{* * *}$ & $0.50 * *$ & -0.17 & 0.25 & 0.04 \\
\hline
\end{tabular}

Note: * indicates significance at the $5 \%$ level, ** indicates significance at the $1 \%$ level 
Table 4: Skewness of the Market Segments Ranked by Beta Shift Coefficient

\begin{tabular}{|c|c|c|c|c|c|c|c|c|}
\hline \multirow[b]{2}{*}{ Market Segment } & \multirow{2}{*}{$\begin{array}{l}\text { Beta } \\
\text { Shift }\end{array}$} & \multirow{2}{*}{$\begin{array}{c}\text { Overall } \\
\text { Skewness }\end{array}$} & \multicolumn{3}{|c|}{ Volatile } & \multicolumn{3}{|c|}{ Calm } \\
\hline & & & Up & Down & Overall & Up & Down & Overall \\
\hline Offices City of London & -0.31 & -1.09 & 1.07 & -0.75 & 0.32 & 2.20 & -3.76 & -2.55 \\
\hline Offices West End & -0.15 & 0.82 & 1.73 & -1.67 & 0.62 & 0.60 & -0.12 & -0.45 \\
\hline Offices Inner South East & -0.12 & -0.23 & -0.01 & -1.91 & -0.09 & -0.29 & -0.06 & -0.27 \\
\hline Retail Central London & -0.07 & 0.47 & 2.16 & -1.20 & 0.50 & 1.14 & -0.23 & -0.08 \\
\hline Offices Mid-Town & -0.05 & 0.04 & 1.03 & -2.01 & 0.20 & 0.47 & -0.98 & -0.49 \\
\hline Industrials London & -0.03 & 1.44 & 2.42 & -0.25 & 1.21 & 1.04 & -0.36 & 0.67 \\
\hline Industrials Eastern & -0.03 & 0.88 & 0.83 & -1.74 & 0.39 & 1.40 & -0.93 & 0.68 \\
\hline Industrials Inner South East & -0.02 & 0.46 & 0.79 & -0.35 & 0.52 & 0.29 & -0.40 & 0.01 \\
\hline Offices Rest of London & 0.01 & 0.52 & -0.43 & -0.28 & 0.59 & -0.69 & 0.15 & -0.30 \\
\hline Retail North East & 0.02 & 0.32 & 0.64 & -1.81 & 0.32 & -1.60 & 1.57 & 0.02 \\
\hline Offices Outer South Eeast & 0.03 & 0.80 & 0.55 & -1.47 & 0.50 & 0.69 & 0.83 & 0.20 \\
\hline Retail Rest of London & 0.05 & 1.02 & -0.08 & -0.58 & 0.31 & 2.43 & 0.11 & 1.68 \\
\hline Retail North West & 0.05 & 1.65 & 2.00 & -1.80 & 1.36 & -0.81 & 1.19 & 0.20 \\
\hline Retail Eastern & 0.05 & 0.86 & 0.96 & 0.04 & 0.67 & 2.01 & -1.24 & 0.07 \\
\hline Industrials Outer South Easte & 0.07 & 0.92 & 0.94 & -0.30 & 0.57 & 0.83 & 1.03 & 0.39 \\
\hline Offices Eastern & 0.08 & 2.38 & 3.06 & -0.19 & 1.85 & -1.30 & -0.33 & -0.37 \\
\hline Retail South West & 0.09 & 0.77 & 0.95 & -0.70 & 0.45 & -0.50 & 0.31 & -0.16 \\
\hline Offices South West & 0.09 & 0.34 & -0.26 & -1.11 & -0.07 & 0.84 & 0.99 & 1.11 \\
\hline Retail Scotland & 0.09 & 1.91 & 1.96 & -0.49 & 1.48 & 1.31 & 0.50 & 1.11 \\
\hline Offi ces Midlands \& Wales & 0.09 & 1.69 & 0.38 & 0.60 & 0.55 & 2.55 & -0.38 & 2.89 \\
\hline Retail Outer South East & 0.10 & 1.44 & 0.77 & -0.09 & 0.68 & 3.11 & 0.61 & 1.46 \\
\hline Retail Yorkshire \&Humberside & 0.10 & 1.02 & -0.04 & -0.05 & 0.37 & 1.80 & -0.29 & 1.29 \\
\hline Offices Scotland & 0.10 & 1.49 & 1.67 & -0.14 & 0.96 & 1.24 & 0.05 & 1.18 \\
\hline Retail West Midlands & 0.10 & 1.21 & 1.96 & 0.48 & 0.96 & 0.93 & 1.34 & 0.47 \\
\hline Retail Inner South East & 0.11 & 1.20 & 0.12 & 0.13 & 0.72 & 1.46 & -1.06 & 0.67 \\
\hline Retail Wales & 0.12 & 1.37 & 1.62 & 0.24 & 1.04 & 2.29 & 0.23 & 1.23 \\
\hline Industrials South West & 0.16 & 1.75 & 0.84 & -0.89 & 0.94 & 0.94 & -1.59 & 0.38 \\
\hline Industrials Midlands \& Wales & 0.18 & 1.43 & 0.56 & -0.65 & 0.54 & 1.27 & -0.53 & 0.80 \\
\hline Retail East Midlands & 0.18 & 2.03 & 1.49 & -0.45 & 1.28 & 0.86 & -0.16 & 0.60 \\
\hline Offices Rest of England & 0.19 & 1.74 & 1.00 & -0.21 & 0.76 & 2.32 & 2.57 & 2.47 \\
\hline Industrials Northeast \&Scotland & 0.23 & 1.43 & -0.30 & -1.01 & 0.30 & 2.18 & 1.14 & 1.99 \\
\hline Average & & $\mathbf{1 . 0 3}$ & 0.98 & -0.66 & $\mathbf{0 . 6 7}$ & $\mathbf{1 . 0 0}$ & $\mathbf{0 . 0 1}$ & 0.54 \\
\hline Correlation with Beta Shift Coe & ficient & $0.68^{* * *}$ & -0.14 & $0.51 * *$ & $\mathbf{0 . 3 7 *}$ & $0.39 *$ & 0.24 & $\mathbf{0 . 6 8 * *}$ \\
\hline
\end{tabular}

Note: $*$ indicates significance at the $5 \%$ level, ** indicates significance at the $1 \%$ level 
Table 5: Tracking Error Risk of the Market Segments Ranked by Beta Shift Coefficient

\begin{tabular}{|c|c|c|c|c|c|c|c|c|}
\hline \multirow[b]{2}{*}{ Market Segment } & \multirow{2}{*}{$\begin{array}{c}\text { Beta } \\
\text { Shift }\end{array}$} & \multirow{2}{*}{$\begin{array}{c}\text { Overall } \\
\text { TER }\end{array}$} & \multicolumn{3}{|c|}{ Volatile } & \multicolumn{3}{|c|}{ Calm } \\
\hline & & & Up & Down & Overall & $\mathbf{U p}$ & Down & Overall \\
\hline Offices City of London & -0.31 & 1.30 & 1.63 & 1.26 & 1.49 & 0.92 & 1.33 & 1.39 \\
\hline Offices West End & -0.15 & 1.03 & 1.99 & 0.95 & 1.71 & 0.53 & 0.81 & 1.15 \\
\hline Offices Inner South East & -0.12 & 0.50 & 0.82 & 0.65 & 0.74 & 0.37 & 0.40 & 0.76 \\
\hline Retail Central London & -0.07 & 0.97 & 1.65 & 1.35 & 1.49 & 0.66 & 0.80 & 0.73 \\
\hline Offices Mid-Town & -0.05 & 1.15 & 1.45 & 1.24 & 1.65 & 0.88 & 0.95 & 1.21 \\
\hline Industrials London & -0.03 & 0.69 & 1.46 & 0.64 & 1.11 & 0.56 & 0.40 & 0.97 \\
\hline Industrials Eastern & -0.03 & 0.72 & 1.39 & 0.73 & 1.16 & 0.61 & 0.37 & 0.69 \\
\hline Industrials Inner South East & -0.02 & 0.61 & 0.99 & 0.55 & 0.79 & 0.55 & 0.52 & 0.85 \\
\hline Offices Rest of London & 0.01 & 0.70 & 1.33 & 0.56 & 1.00 & 0.49 & 0.62 & 0.95 \\
\hline Retail North East & 0.02 & 0.85 & 1.04 & 0.69 & 1.02 & 0.75 & 0.76 & 0.87 \\
\hline Offices Outer South Eeast & 0.03 & 0.73 & 1.22 & 0.58 & 0.94 & 0.54 & 0.71 & 0.76 \\
\hline Retail Rest of London & 0.05 & 0.48 & 0.56 & 0.33 & 0.56 & 0.57 & 0.32 & 0.67 \\
\hline Retail North West & 0.05 & 0.72 & 1.38 & 0.45 & 1.04 & 0.60 & 0.56 & 0.69 \\
\hline Retail Eastern & 0.05 & 0.55 & 0.90 & 0.49 & 0.75 & 0.45 & 0.50 & 0.60 \\
\hline Industrials Outer South Easte & 0.07 & 0.67 & 1.08 & 0.56 & 0.85 & 0.51 & 0.66 & 0.63 \\
\hline Offices Eastern & 0.08 & 1.04 & 2.21 & 0.79 & 1.67 & 0.90 & 0.55 & 0.77 \\
\hline Retail South West & 0.09 & 0.49 & 0.69 & 0.59 & 0.69 & 0.34 & 0.45 & 0.55 \\
\hline Offices South West & 0.09 & 0.85 & 1.30 & 1.33 & 1.36 & 0.73 & 0.47 & 0.67 \\
\hline Retail Scotland & 0.09 & 0.72 & 1.26 & 0.56 & 1.03 & 0.62 & 0.54 & 0.65 \\
\hline Offices Midlands \& Wales & 0.09 & 0.86 & 1.39 & 0.93 & 1.20 & 0.91 & 0.44 & 0.99 \\
\hline Retail Outer South East & 0.10 & 0.57 & 0.99 & 0.47 & 0.79 & 0.50 & 0.45 & 0.58 \\
\hline Retail Yorkshire \&Humberside & 0.10 & 0.57 & 0.82 & 0.64 & 0.76 & 0.54 & 0.43 & 0.58 \\
\hline Offices Scotland & 0.10 & 0.88 & 1.45 & 0.67 & 1.11 & 0.96 & 0.57 & 0.95 \\
\hline Retail West Midlands & 0.10 & 0.56 & 0.75 & 0.56 & 0.74 & 0.42 & 0.55 & 0.49 \\
\hline Retail Inner South East & 0.11 & 0.60 & 1.17 & 0.55 & 0.91 & 0.53 & 0.40 & 0.84 \\
\hline Retail Wa les & 0.12 & 0.78 & 0.87 & 0.69 & 0.99 & 0.72 & 0.66 & 0.93 \\
\hline Industrials South West & 0.16 & 0.72 & 1.46 & 0.47 & 1.06 & 0.57 & 0.44 & 0.68 \\
\hline Industrials Midlands \& Wales & 0.18 & 0.73 & 1.32 & 0.73 & 1.05 & 0.56 & 0.49 & 0.67 \\
\hline Retail East Midlands & 0.18 & 0.65 & 1.22 & 0.63 & 1.00 & 0.51 & 0.42 & 0.55 \\
\hline Offices Rest of England & 0.19 & 1.02 & 1.35 & 0.74 & 1.07 & 1.13 & 0.85 & 0.95 \\
\hline Industrials Northeast $\&$ Scotland & 0.23 & 0.75 & 1.07 & 0.74 & 0.90 & 0.71 & 0.55 & 0.76 \\
\hline Average & & 0.76 & 1.23 & 0.71 & 1.05 & $\mathbf{0 . 6 3}$ & $\mathbf{0 . 5 8}$ & $\mathbf{0 . 7 9}$ \\
\hline Correlation with Beta Shift Co & ficient & -0.11 & -0.27 & -0.19 & -0.25 & 0.06 & -0.19 & $-0.38 *$ \\
\hline
\end{tabular}

Note: $*$ indicates significance at the $5 \%$ level, **indicates significance at the $1 \%$ level 